\title{
Sharing Resources to Support the Teaching of Academic Skills Across the Curriculum
}

\section{Helen Howard}

Skills@Library, University of Leeds, UK

\section{Michelle Schneider}

Skills@Library, University of Leeds, UK

\begin{abstract}
In 2010, Leeds University Library introduced an academic skills strategy with the ambition of embedding academic skills into the curriculum across all faculties for all students. This case study outlines one of the approaches taken by Skills@Library to support the implementation of the strategy. An online portfolio of teaching resources designed to encourage and support academic staff to embed skills teaching in the curriculum was developed. The case study describes the way in which the resource was designed and developed. Feedback received thus far and plans for the future are also discussed.
\end{abstract}

Keywords: academic skills; curriculum; embedding; teaching resources; learning development, open educational resources.

\section{Supporting academic staff to embed academic skills into the curriculum}

The need for students to develop generic and transferable skills alongside subject knowledge has become an integral part of their university experience. This is highlighted by both the Quality Assurance Agency for Higher Education (QAA) and graduate employers. The QAA's UK quality code for Higher Education (2011) emphasises that students graduating with a Bachelor's degree with honours will not just demonstrate extensive knowledge of their subject area, but will be equipped with a range of academic and professional skills, including critical evaluation, problem-solving and communication. Employers are also keen for graduates to have a range of skills and for these to be embedded in all degree programmes: 
Employers need graduates who are equipped with a range of core work skills as well as academic ability. It is these competencies, such as interpersonal skills, communication skills, team-working and customer awareness which, in the final analysis, make graduates employable (Association of Graduate Recruiters, 2010, p.5).

Like many units supporting student academic skills development, Skills@Library at the University of Leeds provides a range of online resources for student use, alongside faceto-face support through teaching in the curriculum, workshops and one-to-one sessions. Over 1000 students a year self-select or are recommended by their lecturers to attend our programme of free, bookable, academic skills workshops. In addition, the online studentfacing resources are well-used in different ways: self-directed by students, as part of blended learning approaches or following recommendation by library and academic staff. These workshops and online resources allow large numbers of students to access skills support.

However, evidence has shown that 'learning how to study effectively cannot be separated from subject content and the process of learning' (Wingate, 2006). Indeed Cottrell (2001, p.3) argues that for skills teaching to be effective it must be linked to assessment and 'well anchored and contextualized within the subject specialism'. It is therefore essential to work closely with academic staff to achieve this. However, Star and Hammer (2008, p.238) identify potential difficulties with this, such as the need to resolve where the responsibility for skills teaching lies, financial and training implications, and possible negative student attitudes to skills teaching. Careful consideration must therefore be given to how best to collaborate with academic staff and improve support for them, to enable them to integrate and deliver skills teaching within the curriculum.

In 2010, Leeds University Library developed an academic skills strategy which has at its heart the ambition to see academic skills embedded within the curriculum across all faculties for all students. This follows on from an Information Literacy strategy developed in 2003 which was successful in embedding information skills support into numerous modules across the university. The academic skills strategy aims to build on the teaching that subject librarians and academic skills advisors already undertake in modules across schools and faculties, as well as the support provided directly by academic staff. To ensure this model is both sustainable and scalable, Skills@Library must collaborate 
effectively with academic staff and find innovative ways to encourage and support them to embed skills teaching within the curriculum.

\section{The Lecturer webpages concept: an online portfolio of teaching resources}

Skills@Library has made available a set of teaching resources aimed at academic staff to download, adapt and embed within their teaching. These Lecturer webpages provide a bank of ready-made workshops, complete with lesson plans, slides and hand-outs, as well as short standalone activities. The resources cover topics such as finding and evaluating information, presentation and writing skills. All resources on the Lecturer webpages are generic and designed to be reused and tailored to any discipline. The content is freely available and staff can use as much (a whole workshop) or as little (a single activity) as they wish to. As well as face-to-face teaching materials, online options are also provided for use in blended learning. There are different options for working with this material: staff can take a whole workshop and run it off the shelf; alternatively, they can take part of a workshop or a single activity and adapt it for their needs; or they can work with Skills@Library staff to devise tailored support for a particular group of students, designing and delivering support collaboratively.

\section{Development of the Lecturer webpages}

The Skills@Library Team worked collaboratively, but with clear roles, to produce the resource. The team considered how best to present the materials and it was agreed to develop a new set of webpages which would mirror the topic areas covered on our existing student webpages (for example, writing skills, referencing, presentation skills etc.). A template for the matching Lecturer webpages, as well as templates for presenting the content that would sit within the pages, were developed by the e-learning staff. The actual content was provided by academic skills advisors who looked at the workshops they had run in the previous year and developed detailed lesson plans for each, as well as updating presentations and hand-outs, ensuring that these were generic and adaptable. All the content was proofread by the team leader, and then uploaded to the webpages by the elearning staff. 
Each topic page is laid out in a consistent way to help users become quickly familiar with the navigation and the way the content is packaged together. The topic pages are split into five sections, so that users are not overwhelmed by all the teaching materials at once, but can select which section to explore first. The five sections are:

1. Workshops: lesson plans, slides and hand-outs.

2. Individual face-to-face activities.

3. Online activities for independent or blended learning.

4. Supporting resources: books, journals and websites.

5. Related topics.

Figure 1. Lecturer page.

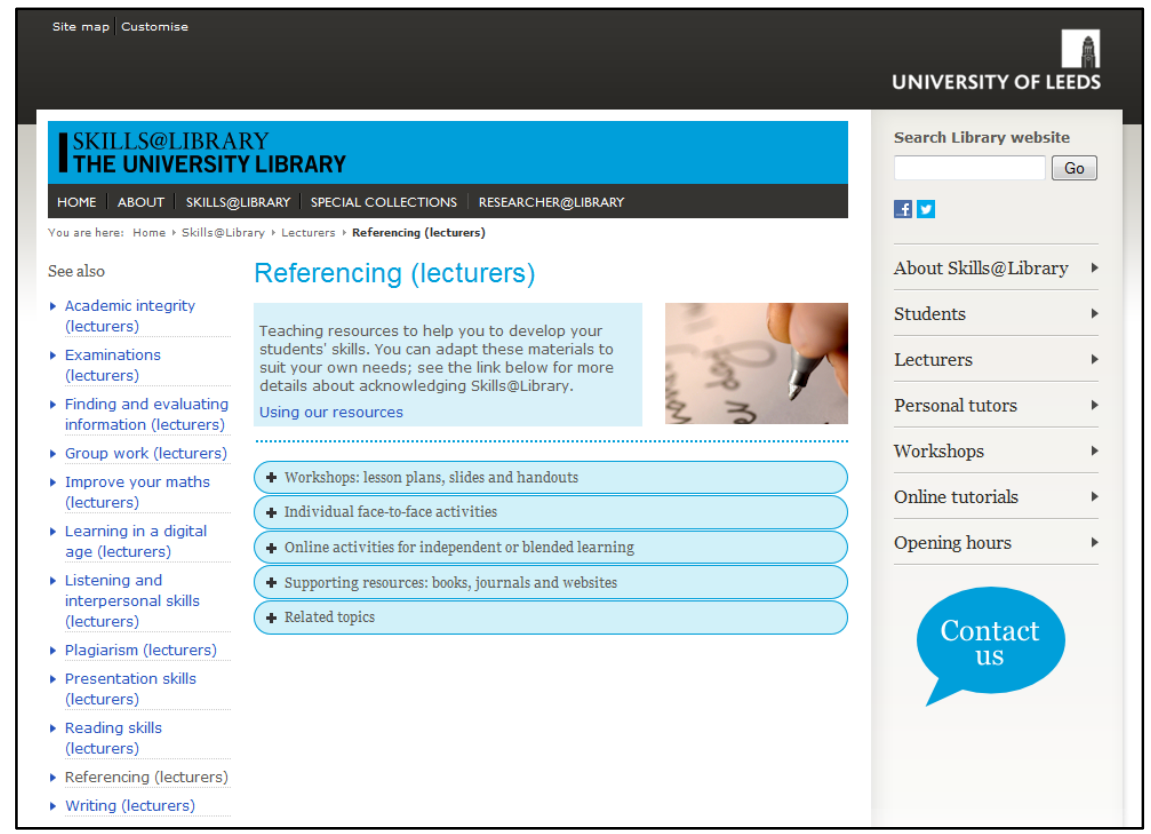

Figure 2. Lesson plan.

SKILLS@LIBRARY

THE UNIVERSITY LIBRARY

Skills@Library Workshop: Interpreting assignments and finding information

This workshop is aimed mainly at first and second year undergraduates. This session should be done in a PC cluster, however until activity 5 they do not need to use a PC, therefore you can run the initial part of the session in a lecture or seminar and get them to do the online activities following the session. We have used a generic assignment tittle for our example which can be adapted to reflect the assignments that are representative of your subject area.

All the activities can be adapted to reflect your subject area.

Aims: By the end of this session students should be:

- Able to analyse an assignment in order to find out what it requires the student to write about

- Able to plan out their topic and identify keywords and phrases to search with

- Made aware of the different information sources and how you decide what's appropriate for acadernic use

- Be able to apply search techniques to find books and journals in the Library Catalogue and in databases

Time: $1.5 \mathrm{hr}$

Supporting materials:

- Powerpoint for tutor

- Powerpoint for students

Gol Cautionl Stopl Handout (A3, colot

Keyword search lmoroving nou, colour 
Within the workshops section, users will find complete workshops with detailed lesson plans containing links to all relevant material including slides and hand-outs.

For users who do not need a complete session focusing on one topic, or who just require some new ideas for sessions they already teach, we provide shorter stand-alone activities with accompanying teaching notes, suggesting how these activities could be used, as well as any other material needed to run the activity. These can be incorporated into existing workshops, curriculum sessions or used as part of new teaching sessions. All the material can be downloaded and saved, then used or adapted with acknowledgement to Skills@Library.

Developing students as independent learners and providing blended learning opportunities are also important at the University of Leeds, so the third section provides lecturers with online activities, again with accompanying teaching notes, which offer suggestions of how the resources can best be used with students. Academic staff can refer their students directly to the online resources or integrate them within their modules, for example, in a VLE area. The final two sections give lecturers links to further resources (books, journals and websites), related lecturer topic pages and links to LearnHigher resources in the area.

After discussion, the team decided to share the resources under a Creative Commons licence, allowing anyone to use them for non-commercial purposes and modify them, providing Skills@Library is attributed as the source of the work (CC BY-NC 3.0: http://creativecommons.org/licenses/by-nc/3.0/). Information on using the resources and how they should be attributed is also provided on the website.

This model could be adopted by other institutions wishing to share teaching materials, as it takes a simple web-based approach to presenting and making available related resources. Teaching staff need to provide up-to-date, preferably tried and tested, teaching and learning materials, including detailed lesson plans which provide sufficient guidance for others to run the sessions. Some expertise in webpage creation, maintenance and the uploading of documents is required, and consideration should be given to the time commitment needed to keep materials up-to-date, thus administrative and e-learning support is useful. Depending on the institution, the use of an in-house or national repository for housing Open Educational Resources may be more appropriate. 


\section{Feedback and evaluation}

The Lecturer webpages were launched at an event organised by Skills@Library in December 2010 which was attended by academics and the Pro Vice Chancellor for Student Education. Each attendee at the launch was given a chance to explore the resource on a PC and asked to record their comments, feedback or observations on a blank postcard. The resources received many positive comments, including:

Excellent, lots of good ideas/materials to support development of research skills...Can see ways this material can be integrated into existing modules through level 1 - 2. (Participant, launch event, 2010)

Since the launch, the resource has been presented to academic staff at the internal Student Education Conference at the university (Howard and Schneider, 2012a), as well as the Association for Learning Development in Higher Education (AldinHE) (Howard and Schneider, 2012b) conference and the Librarians' Information Literacy Annual Conference (LILAC) (Schneider, 2012). Again, every participant was given a chance to explore the Lecturer webpages and asked to record their thoughts on the blank postcard. The resource was well received, with comments including:

I am amazed at the resources that are available to be used for teaching and supporting students...I will definitely use materials for referencing and writing skills, especially the face-to-face ones. (Participant, University of Leeds Student Education Conference, 2012)

Well-structured with well thought out resources and activities. (Participant, ALDinHE Conference, 2012)

The layout is really good, very professional looking! Good to see that the resources are consistently presented too, with the same process - lesson plans etc. (Participant, LILAC Conference, 2012)

Participants could certainly see the value in having these types of resources openly available: 
I liked the visual nature of much of your material, and the use of examples. I am especially interested in the sections on academic writing, because this is the topic (in all aspects) which students most often consult me about 1-to-1.

(Participant, ALDinHE Conference, 2012)

There is a really good range of resources available that could be useful for lecturers looking for ideas in how to get started in teaching a topic. Potentially saving time in developing their own resources. (Participant, University of Leeds Student Education Conference, 2012)

In the six months from January to June 2012, the resource has received 6,193 visits with 3,882 unique visitors. Both librarians and academics have used the teaching materials; below are just two comments we received after seeking some informal feedback from two users about their experience of the Lecturer pages:

Using the materials cut down my preparation time a great deal and gave the students more support in that they got a variety of materials to look at; so I found it very useful. (Lecturer, School of Law, University of Leeds)

The Skills@Library Lecturer pages have been really useful in providing me with material that I can just pick up and use or adapt in my teaching. (Faculty Team Librarian, Leeds University Library)

The impact of the Lecturer webpages has also spread beyond the University of Leeds. The Skills@Library Team were honoured to receive the Credo Reference Digital Award for Information Literacy for the resource, presented at LILAC in April 2012. The award recognises an individual librarian or group of librarians who develop the best new digital resource for promoting information literacy. Statistics also show that the pages have been accessed both nationally and internationally.

Whilst the Lecturer webpages have been well received, we have also gathered useful feedback from staff, and at the conferences, about how the resources can be developed and improved. Many comments suggested that users would benefit from case studies explaining how others had used, adapted and integrated the resources into their teaching. In addition, there are topic areas that could be expanded, such as writing skills, to provide 
a broader range of examples in a variety of disciplines and assignment types, such as literature reviews and report writing.

\section{Future plans}

The Lecturer webpages are not a finite, static resource; they will always be in development. Over the coming year, we will be expanding some of our topic areas such as writing, as well as developing resources in other key skills areas such as time management. In response to a number of comments received, we will be gathering case studies from academics and other staff involved in student support who have used the resources. In addition, we will continue to monitor usage, look into new ways to publicise the resource and investigate more robust ways to evaluate the impact of this resource on students' academic skills development.

\section{Conclusion}

The Lecturer webpages provide an innovative way of supporting academic staff in the delivery of academic skills teaching. They reflect our belief that academic skills development in students is a shared responsibility between academic staff and central learning development staff. Far from being prescriptive, staff can decide to what extent they wish to use the materials independently or collaboratively with Skills@Library. It is hoped that the Lecturer webpages will not only help academic staff to teach academic skills, but will encourage them to embed skills within the curriculum, thus supporting the central aim of our academic skills strategy. Furthermore, the resource provides an opportunity to showcase the creative and interactive approaches to teaching that Leeds University Library has developed. Finally, as the webpages are publicly available, this is a resource that academics and librarians can use across institutions both nationally and internationally; they demonstrate the potential to share best practice and avoid reinventing the wheel. 


\section{References}

Association of Graduate Recruiters (2010) Talent, opportunity, prosperity. A manifesto for graduate recruitment [Online]. Available at: http://www.agr.org.uk/Content/AGR-Amanifesto-for-graduaterecruitment (Accessed: 26 October 2011).

Cottrell, S. (2001) Teaching study skills and supporting learning. Basingstoke: Palgrave.

Howard, H. and Schneider, M. (2012a) 'Don't reinvent the wheel: resources to support the teaching of information literacy and academic skills across the curriculum', Excellence: Student Education Conference. University of Leeds, 6 January.

Howard, H. and Schneider, M. (2012b) 'Don't reinvent the wheel: resources to support the teaching of information literacy and academic skills across the curriculum', Learning Development in a digital age: emerging literacies and learning spaces: 9th ALDinHE Conference. University of Leeds, 2-4 April.

Leeds University Library (2010) Academic skills strategy [Online]. Available at: http://library.leeds.ac.uk/library-academic-skills-strategy (Accessed: 28 February 2012).

The Quality Assurance Agency for Higher Education (2011) UK quality code for higher education [Online]. Available at:

http://www.qaa.ac.uk/Publications/InformationAndGuidance/Documents/QualityCode-Chapter-A1.pdf (Accessed: 27 June 2012).

Schneider, M. (2012) 'Don't reinvent the wheel: resources to support the teaching of information literacy and academic skills across the curriculum', LILAC. Glasgow Caledonian University, 11-13 April.

Star, C. and Hammer, S. (2008) 'Teaching generic skills: eroding the higher purpose of universities, or an opportunity for renewal?', Oxford Review of Education, 34(1), pp. 237-251. 
Wingate, U. (2006) 'Doing away with 'study skills", Teaching in Higher Education, 11(4), pp. 457-469.

\section{Author details}

Helen Howard has led the Skills@Library Team at the University of Leeds since 2009. As Team Leader, her role involves co-ordinating Skills@Library activities within the university, particularly workshops, teaching and online learning resources, to promote academic skills development in students.

Michelle Schneider is Academic Skills Development Officer at Skills@Library, University of Leeds. She supports students' academic skills development through the delivery of face-to-face workshops and one-to-one advice, as well as developing online resources. Her role also involves working with the Faculty Team Librarians to deliver academic skills within the curriculum. 